\title{
OBITUARIO
}

\section{José Sanmartín Esplugues, un pionero de la filosofía de la tecnología en España}

\author{
ANTONIO DIÉGUEZ \\ UNIVERSIDAD DE MÁLAGA
}

El pasado 19 de agosto de 2020 falleció el filósofo de la ciencia y de la tecnología José Sanmartín Esplugues, uno de los autores más influyentes y más citados del panorama filosófico español. José Sanmartín nació en Valencia el 17 de marzo de 1948. Se licenció en Filosofía en la Universidad de Valencia (1965-1970) y se doctoró en 1972 en la misma universidad con una tesis sobre la hipótesis del continuo. Poco después, en 1975, obtuvo una beca von Humboldt y se marchó a Aachen (Aquisgrán). Allí empezó trabajando sobre la escuela de Erlangen y la teoría de modelos, pero pronto empezó a interesarse por los estudios de Ciencia, Tecnología y Sociedad y por la filosofía de la biología.

Fue uno de los miembros fundadores del INVESCIT en 1985, que constituyó un primer intento de institucionalizar en España los estudios CTS. En los tres años siguientes realizó una estancia de investigación como investigador invitado en el Instituto Max Planck de Fisiología de la Conducta de Seewiesen y de Etología Humana, en Andechs. Durante su estancia en el primero, conoció y recibió la influencia de I. Eibl-Eibesfeldt y de W. Schiefenhövel, influencia que, según dice en algún lugar, fue «equilibrada hasta cierto punto por las lecturas de S. J. Gould, R. Lewontin y otros».

\footnotetext{
(C) Contrastes. Revista Internacional de Filosofía, vol. XXV No2 (2020), pp. 157-159. ISSN: 1136-4076 Departamento de Filosofía, Universidad de Málaga, Facultad de Filosofía y Letras Campus de Teatinos, E-29071 Málaga (España)
} 
En 1987 la editorial Anthropos publicó uno de sus libros más influyentes entre los filósofos de la tecnología, Los nuevos redentores: reflexiones sobre la ingeniería genética, la sociobiología y el mundo feliz que nos prometen. Algunas de las tesis que se discuten hoy en torno al transhumanismo y al mejoramiento humano estaban ya claramente expuestas, analizadas y criticadas en este libro. Sanmartín argumentaba en él que la ciencia es un instrumento de dominio del mundo y que en ocasiones sus promesas de transformación tecnológica de la realidad son asumidas sin la debida reflexión y sin percibir los intereses económicos que hay detrás. Estos temas tuvieron un tratamiento renovado en su libro de 1990 Tecnología y futuro humano, publicado por la misma editorial. En 1988 la revista Anthropos, de esa editorial, dedicó dos números monográficos a su pensamiento.

Entre los años 1995 y 1997 fue Conseller de Trabajo y Asuntos Sociales de la Comunidad Valenciana y esto le mantuvo retirado por un tiempo de la investigación. En 1997, y hasta 2009, asumió la dirección del Centro Reina Sofía para el Estudio de la Violencia. A partir de entonces sus intereses investigadores se centraron en el análisis de la violencia desde un punto de vista filosófico y multidisciplinar. Distinguió claramente entre la agresividad, que sería un fenómeno fundamentalmente biológico, innato e instintivo, y la violencia, que sería un acto intencional y dañino procedente de la modulación cultural de la agresividad y en la que lo biológico prácticamente desaparece. Se interesó por las bases neurológicas de ambos tipos de conducta. Fruto de aquellos años fueron sus libros más conocidos, especialmente La violencia y sus claves, publicado en el 2000 y que tras diversas reediciones apareció de nuevoe en una versión actualizada en 2013 en la editorial Ariel. A este libro siguieron La mente de los violentos (2002), El terrorista (2005), y El enemigo en casa (2008).

Coordinó también durante esos años diversas obras colectivas, especialmente sobre la violencia en sus diversas facetas. Entre ellas cabe destacar New Worlds, New Technologies, New Issues (Associated University Presses, 1992), Violence: From Biology to Society (Elsevier, 1997), Violence and Psychopathy (Kluwer, 2001), Reflexiones sobre la violencia (Siglo XXI México, 2010), Técnica y ser humano (Centro Lombardo Toledano, México, 2017). Escribió también diversos artículos sobre filosofía y cine.

De sus diversos cargos académicos señalaré solo dos: entre 1993 y 1995 presidió la Society for Philosophy and Technology y en 2008 fue nombrado rector de la Universidad Internacional de València (VIU).

Aunque resulta difícil escoger uno de sus libros para presentar su pensamiento al lector que no lo conociera, me decido por recomendar uno de los últimos, que, hasta cierto punto, resume una buena parte de su legado filosófico. Me refiero a El exceso de excluir la razón. Reflexiones para una 
historia de la filosofia de la ciencia, publicado en México en 2013 por el Centro de Estudios Vicente Lombardo Toledano (cuyo pdf puede descargarse gratuitamente en el siguiente enlace: https://www.centrolombardo.edu.mx/ el-exceso-de-excluir-a-la-razon-reflexiones-para-una-historia-de-la-filosofiade-la-ciencia/ ).

Me parece que no sería inoportuno cerrar este breve recordatorio de quien fue no solo un afable colega, sino un buen amigo con el que compartí muchas cosas, entre ellas nuestro interés por la biotecnología y por el pensamiento de Ortega, con una cita autobiográfica tomada del libro que acabo de mencionar:

Me declaro un naturalista practicante, pero un naturalista sensato. Pienso que la filosofía y, en particular, la filosofía de la ciencia deberían dar acomodo a aquellas áreas del saber y técnicas que pudieran enriquecer su discurso. Tras pasar un cierto tiempo en el instituto creado por Konrad Lorenz en Seewiesen (junto a la bellísima ciudad de Starnberg) creo que no sólo sé, sino que tengo asimismo la impresión de que jamás pensó que sus desarrollos científicos pudieran suplir la grandeza filosófica de Kant. Todo lo contrario. Lorenz creyó que desde la biología y, en particular, desde la etología humana podía contribuir a que se afianzase una parte un tanto débil del pensamiento kantiano: el origen del a priori.

¿Por qué no valernos en filosofía de la ayuda de la ciencia? Estoy firmemente convencido de que hay que hacerlo. Ya he dicho que soy un naturalista sensato, por eso mismo creo en la ayuda, pero no en la sustitución. 
